\title{
Herstelcirkel in de wijk
}

\section{Een andere diabetesaanpak}

\author{
Anne Kuijpers $\cdot$ Henk Schers
}

Published online: 11 February 2019

(C) The Author(s) 2019

\begin{abstract}
Diabetes is een groeiend probleem dat een groot beroep doet op de zorg. Het project Herstelcirkel probeert het initiatief bij de deelnemers te leggen en de verantwoordelijkheid meer naar het maatschappelijk domein te verplaatsen. De eerste resultaten zijn positief. Opschaling brengt de nodige uitdagingen met zich mee.
\end{abstract}

\section{Aanleiding}

In Nederland hebben op dit moment meer dan 850.000 mensen diabetes mellitus type 2 (DM2), in de volksmond 'ouderdomssuiker' genoemd. Het ontstaan van DM2 heeft te maken met erfelijke aanleg, maar ook omgevingsfactoren, zoals een ongezonde leefstijl en overgewicht, spelen een zeer belangrijke rol. Mensen met een body mass index boven de 30 hebben een tienmaal hogere kans om diabetes te ontwikkelen dan mensen met een gezond gewicht.

In Nederland worden mensen met DM2 vrijwel zonder uitzondering behandeld in de huisartsenpraktijk. De zorgprofessionals (huisartsen en praktijkondersteuners) volgen daartoe de richtlijnen van het Nederlands Huisartsen Genootschap en zijn gericht op een goede 'instelling' van de diabetes. Bekend is dat een goede instelling leidt tot minder complicaties op de langere termijn. Optimalisering van de bloedsuikerspiegel, cholesterolwaarde en bloeddruk hoort daarbij. In de huisartsenpraktijk wordt ook de nadruk gelegd op leefstijl en gedragsverandering. In de gesprekken met de praktijkondersteuner (poh) passeren vaak thema's als roken, gezonde voeding en lichaamsbeweging. De meeste mensen met diabetes

Anne Kuijpers is in november 2018 overleden.

A. Kuijpers · Dr. H. Schers $(\bowtie)$

Afdeling Eerstelijnsgeneeskunde, Radboudumc, Nijmegen, Nederland

Henk.schers@radboudumc.nl
(>90\%) krijgen daarnaast bloedsuiker- en cholesterolverlagende medicatie voorgeschreven [1]. De door zorgprofessionals aangeboden gedragsmatige interventies zijn echter niet uitgesproken succesvol: het gemiddelde gewicht van mensen met diabetes blijft stijgen en de normen voor gezond bewegen worden vaak niet gehaald [2].

\section{Een andere aanpak}

Wij zijn in Nijmegen in 2016 gestart met Herstelcirkel in de wijk (HCIW; www.herstelcirkel.nl), een groepsgerichte aanpak voor mensen met DM2. Herstelcirkel is een initiatief van zorggroep STIELO (Nijmegen Noord), het Radboudumc, zorgverzekeraar Menzis en zorginnovator Huub ter Haar. In de Herstelcirkel werken mensen met DM2 gedurende minimaal een jaar in groepsverband aan bewustwording, een gezondere leefstijl en verinnerlijking van gedragsverandering. In de tijd dat ze deelnemen aan de Herstelcirkel proberen we de afstand te vergroten tussen de zorg en de deelnemers, omdat onze hypothese is dat de deelnemer ruimte nodig heeft om te groeien in zijn rol. De doelgroep is voorlopig mensen met DM2 in de leeftijdscategorie van 45 tot 75 jaar.

We hebben voor deze aanpak gekozen omdat er aanwijzingen zijn dat mensen met DM2 beter tot gedragsverandering komen met behulp van een groepsaanpak [3, 4]. Mogelijk kan dat ook daadwerkelijk leiden tot leefstijlverandering [5]. Het is dan wel nodig om zo veel mogelijk aan te sluiten bij de behoeften en prioriteiten van mensen met diabetes zelf. De achterliggende gedachte is dat minder gekeken wordt vanuit het oogpunt van ziekte en zorg, en veel meer vanuit gezondheid en gedrag [6]. Zelfherkenning, zelfregulering en zelfbepaling in de context van groepsdynamiek zouden een positief effect hebben op de ervaren gezondheid en de kwaliteit van leven. Daarnaast kun- 
nen zelf gestelde doelen eerder worden behaald dan doelen die door anderen worden gesteld [7, 8].

De deelnemers worden door de poh van de huisarts uitgenodigd om deel te nemen. De aanpak berust op vier pijlers:

1. De zorg op afstand. Deelnemers mogen stoppen met de driemaandelijkse controles en hoeven alleen voor de jaarcontroles naar de huisartsenpraktijk. Zorg wordt ingezet als de deelnemer daar zelf om vraagt. Deelnemers komen daardoor in een andere modus: ze komen niet voor 'passieve' controles in de praktijk, maar kunnen actief aankloppen bij de zorgverlener met vragen en problemen.

2. De patiënt zelf staat aan het roer. Deelnemers worden gestimuleerd om te werken aan zelfmanagement en zelfvertrouwen om 'hun' diabetes zelf te behandelen. De deelnemers stellen daartoe zelf de doelen. Als ze dat willen kunnen de deelnemers ook zelf hun medicatie aanpassen. De ratio daarvoor is dat vaak minder bloedsuiker-, cholesterol- en bloeddrukverlagende medicatie noodzakelijk is als het eetpatroon verandert of het gewicht afneemt.

3. Een coöperatieve groep. De deelnemers vormen een groep van zestien tot twintig deelnemers, die gezamenlijk een aanpak opstellen voor de invulling van het traject van Herstelcirkel. Ze kiezen uit hun midden een of twee 'regisseurs'. Deze bekleden de voorzitter- en coördinatorrollen. De groep kan zo samen besluiten om bijvoorbeeld een avond te organiseren over voeding, verdieping van diabeteskennis of de zin en onzin van medicatie. Om de gezamenlijke verantwoordelijkheid te benadrukken wordt van de deelnemers een bescheiden maandelijkse financiële bijdrage gevraagd. Het idee is dat deze symbolische investering in jezelf leidt tot grotere betrokkenheid en hogere motivatie tot gedragsverandering.

4. Inzet van een Leefkrachtcoach. Het profiel van de Leefkrachtcoach is hbo-opgeleid, kennis en ervaring in coaching, en kennis van voeding, beweging en leefstijl. In deze pilot is de coach bekostigd door de zorgverzekeraar. De coach begeleidt het groepsproces en de deelnemers kunnen individueel gesprekken met de coach aangaan. We hebben de coach 'Leefkrachtcoach' genoemd, omdat leefstijl alleen een te smalle insteek lijkt. Leefkracht bestaat uit het verwerven van regie, energie en een positiever zelfbeeld. Het gaat vaak om het vinden van diepere drijfveren voor gedragsverandering: pijn, verdriet en ingeslepen zelfbeloningsmechanismen staan een duurzame gedragsverandering in de weg.

\section{Projectorganisatie}

In de opstartfase was Herstelcirkel een gezamenlijk initiatief van het Radboudumc, de multidisciplinaire eerstelijnszorggroep STIELO, zorgverzekeraar Menzis en een zorginnovatiebureau.
Na de opstartfase met de pilotgroep van twintig deelnemers is de Stichting Herstelcirkel in de wijk opgericht, die het initiatief verder moet brengen. Herstelcirkel is verantwoordelijk voor de inhoud van het programma en de coaches. Zorggroepen die met Herstelcirkel in zee gaan blijven zelf verantwoordelijk voor de medische zorg die zij leveren. Voor de verdere doorontwikkeling is een subsidie geworven. De coaches worden aangesteld door de Stichting Herstelcirkel. Voor deze coaches is een competentieprofiel opgesteld. Op termijn is de wens om het initiatief ook bestuurlijk veel meer te laten dragen vanuit de deelnemers en de lokale samenleving.

\section{Uitvoering en implementatie}

De medisch professional staat in Herstelcirkel op de achtergrond. De verantwoordelijkheid ligt bij de deelnemer. Hierdoor nemen de controlemomenten voor de professional af. Dat is binnen de zorg uiteraard niet vanzelfsprekend. Herstelcirkel riep bij diverse professionals aanvankelijk dan ook een zeker gevoel van onzekerheid en onveiligheid op. De huisarts blijft eindverantwoordelijk voor de behandeling en begeleiding van de DM2-patiënten, en deze moet dus expliciet toestemming geven voor deelname.

Omdat opschaling geen sinecure is beperken we ons in eerste instantie tot het werkgebied van Menzis. De financiering van de groepen is steeds een onderhandeling tussen zorggroep en zorgverzekeraar. De bedoeling is om de verantwoordelijkheid voor de financiering te gaan verbreden naar gemeenten, ondernemers, werkgevers en andere partijen. Dit doen we omdat we diabetes zien als een maatschappelijk probleem, dat niet enkel vanuit de Zorgverzekeringswet zou moeten worden gefinancierd.

\section{Resultaten}

De resultaten van de eerste pilotgroep van twintig deelnemers stemmen hoopvol. Alle twintig deelnemers bleven gedurende het hele jaar actief binnen de coöperatie. Ze stelden hun doelen vooral op de onderdelen voeding, beweging en het afbouwen van medicatie. Bijna alle deelnemers gaven na afloop aan dat ze hun voedingspatroon hadden veranderd.

\section{Kwantitatief (klinische uitkomsten)}

In de loop van het jaar was er een significante daling van het gemiddelde gewicht van de deelnemers van $93,9 \mathrm{~kg}$ naar $90,5 \mathrm{~kg}(p=0,029)$. Daarmee was er ook een significante daling van de gemiddelde BMI van 30,1 naar 29,0 ( $p=0,008)$. De systolische en diastolische bloeddruk van de deelnemers bleven na 12 maanden vergelijkbaar (ten opzichte van T0 respectievelijk $p=0,09$ en $p=0,808)$. De nuchtere bloedglucosewaarden daalden in het jaar van HCIW van 8,7 naar 8,4 (niet significant). Het totaal- 
cholesterolgehalte en het LDL-gehalte (het 'slechte' cholesterol) bleven vergelijkbaar, het HDL-gehalte (het 'goede' cholesterol) liet een significante stijging zien van 1,2 naar $1,6(p=0,013)$.

De genoemde klinische waarden worden uiteraard beïnvloed door medicatie. Het gebruik van bloedsuiker-, cholesterol- en bloeddrukverlagende medicatie veranderde substantieel gedurende het jaar. Bij de start gebruikten achttien van de twintig deelnemers bloedsuikerverlagende medicatie voor DM2. Zes deelnemers $(35 \%)$ gebruikten na een jaar minder medicatie en vier deelnemers (24\%) stopten hun bloedsuikerverlagende medicatie. Een van de vier deelnemers die bij aanvang insuline gebruikten, stopte daarmee. De andere drie deelnemers minderden het insulinegebruik. Ook cholesterol- en bloeddrukverlagende medicatie werd geregeld geminderd of gestopt.

Naast de klinische uitkomstmaten keken we ook naar zelfredzaamheid en zelfmanagement. De scores op de vragenlijsten voor deze thema's (PAM-13 $[9,10]$, SMP-T2D [11] en DMSES [12, 13] na 6 en 12 maanden, vragenlijsten die deels specifiek zijn voor diabetes) veranderden relatief weinig, maar een deel liet na 12 maanden wel significante veranderingen zien (SMP-T2D na een jaar significante toename $(p=0,012)$, PAM-13 na een jaar significante toename $(p=0,034))$. De ervaren gezondheid (SF-12) veranderde niet $[14,15]$.

\section{Kwalitatief (interviews)}

$\mathrm{Na}$ afloop van het eerste jaar werden alle deelnemers geïnterviewd. Bij de meeste deelnemers was de kennis over diabetes sterk verbeterd en ze hadden meer inzicht in wat diabetes lichamelijk met hen doet. Dit leidde tot een sterke bewustwording van de betekenis van diabetes in het leven.

Voor de meeste deelnemers was het een eyeopener dat ze zelf de regie konden hebben over hun ziekte. De meesten ervoeren het als prettig om zelf de verantwoordelijkheid te hebben en zelf te mogen beslissen hoe te handelen, bijvoorbeeld wat betreft medicatie en voeding. Zelfregie leidde bij bijna iedereen tot meer bewustwording. Die bewustwording betrof vooral het inzicht in wat diabetes is en kennis over voeding. Dankzij deze bewustwording en de toename van kennis hadden deelnemers soms ook het gevoel weer alleen verder te kunnen. Dit gold echter niet voor alle deelnemers: er was ook een aanzienlijke groep die eraan twijfelde of dat zou gaan lukken. Ze ervoeren het proces van een jaar als te kort.

\section{Beschouwing}

Herstelcirkel lijkt een veelbelovende aanpak, die voor een deel van de mensen met DM2 goed inzetbaar is in plaats van een groot deel van het reguliere zorgaanbod. Het kan aldus een modulaire vorm van diabeteszorg zijn, die bestaat naast het reguliere aanbod en waarvoor de verantwoordelijkheid anders is belegd. Deelnemers waren tevreden over hun deelname - de beoogde doelen werden voor een groot deel behaald: het gewicht nam af, de hoeveelheid medicatie werd verminderd, cholesterolwaarden veranderden in de goede richting en de ervaringen van de deelnemers en professionals waren positief. De toename van eigen verantwoordelijkheid en regie leidde tot bewustwording, meer inzicht en vertrouwen bij de deelnemers.

\section{Lessons learned-pilot}

\section{Inhoudelijke doorontwikkeling}

Omdat veel deelnemers aangaven dat ze de tijdsduur van een jaar toch erg kort vonden, hebben we samen met deelnemers gekeken naar de invulling van een vervolg op Herstelcirkel. We zijn gekomen tot een vervolg voor jaar 2 en 3, dat veel minder intensief is en meer initiatief vanuit de deelnemers zelf vraagt: Herstelcirkel+. Opnieuw wordt een eigen financiële bijdrage gevraagd. Modulair worden kennis-, verdiepings- en inspiratiebijeenkomsten georganiseerd, en in voorkomende gevallen kan ook van de coach worden gebruikgemaakt. In Nijmegen Noord hebben we inmiddels drie groepen deelnemers in de zorggroep. Dat maakt verbinding mogelijk tussen de coöperaties onderling, waarmee we burgerinitiatief en burgereigenaarschap verder proberen te stimuleren. Dit leidt tot een bredere gezondheidsbevorderende cultuur in de wijk: er bestaan inmiddels diverse wekelijkse beweegen ontspanningsmomenten die openstaan voor deelnemers uit alle groepen. De groepen leren van elkaar.

\section{Borging}

Er moest een tarief worden vastgesteld. Het totale aantal uren coaching voor een groep van twintig deelnemers bedraagt ongeveer 300 op jaarbasis; daarnaast zijn 60 uur kwartiermaker (coördinator) en enige infrastructurele middelen begroot, bijvoorbeeld voor het huren van ruimtes en het inhuren van sprekers. Per deelnemer betekent dat voor het eerste jaar een bedrag van ongeveer 1.750 euro op jaarbasis.

Verantwoordelijkheden moesten belegd worden. Het is nodig om duidelijk te beschrijven wat de taken en verantwoordelijkheden van de reguliere zorg zijn, en welke taken bij de Herstelcirkel horen. In de eerste plaats is dat van belang voor de deelnemers, zodat ze weten wat ze van de zorgprofessionals mogen verwachten. Daarnaast moet ook juridisch helder zijn wat er is afgesproken.

\section{Opschaling}

Inmiddels zijn er tien coöperaties opgestart of in een ver stadium van voorbereiding en oprichting. De gesprekken met zorggroepen en de onderhandelingen tussen zorggroepen en zorgverzekeraars vergen veel tijd - meer dan we dachten. De werving van de deelnemers loopt tot nu toe voornamelijk via de poh's van 
de huisartsen. Andere vormen van werving, zoals een publieksavond in de wijk en via het aanschrijven van alle mensen met diabetes uit de zorggroep, bleek bij onze aanpak niet erg succesvol. Blijkbaar is het toch een grote stap voor potentiële deelnemers om uit de comfortzone te komen. De persoonlijk benadering door de poh is daarentegen wel succesvol.

Al tijdens de projectfase moest er over opschaling worden nagedacht, anders zou het gat tussen projecteinde en het vervolg veel te groot worden. Tegelijkertijd waren de uitkomsten van de wetenschappelijke evaluatie noodzakelijk voor opschaling omdat er anders geen investeerders waren. Tijdens de opschaling en continueringsfase zijn andere mensen met andere competenties nodig: de basis moet op orde zijn en het programma moet kloppen, er moeten opnieuw financiën geworven worden, het doorstarten en opschalen kosten veel tijd en energie. Ook moet in een vroeg stadium worden nagedacht over nieuwe kwartiermakers en ambassadeurs. Er moeten vaak scherpe prioriteiten gesteld worden. Veel mensen hebben interesse in ons project getoond en we hebben er soms ook voor moeten kiezen om bepaalde dingen niet te doen.

\section{Conclusie}

De Herstelcirkel heeft veelbelovende eerste resultaten opgeleverd. Deze aanpak creëert een verandering van bewustwording en verantwoordelijkheden, waarmee de noodzakelijke verschuiving van diabetes als medisch probleem naar diabetes als maatschappelijk probleem in gang wordt gezet. Het opschalen kost veel organisatie en tijd. Op termijn willen we naar een aanpak op maat binnen de groepsdynamiek.

Het concept Herstelcirkel wordt versterkt door het verbreden van eigenaarschap en een heldere regie. De symbolische meerwaarde van het project reikt verder en blijkt een inspiratiebron voor andere initiatieven in het land. Erkenning vanuit de zorg is cruciaal voor de verdere doorontwikkeling en dat vergt deels een andere opleiding en training van professionals, waarbij het gemeengoed moet worden dat mensen met diabetes meer ruimte en verantwoordelijkheid krijgen. Tegelijkertijd is de verschuiving naar meer maatschappelijke verantwoordelijkheid onontkoombaar.

Open Access This article is distributed under the terms of the Creative Commons Attribution 4.0 International License (http://creativecommons.org/licenses/by/4.0/), which permits unrestricted use, distribution, and reproduction in any medium, provided you give appropriate credit to the original author(s) and the source, provide a link to the Creative Commons license, and indicate if changes were made.

\section{Literatuur}

1. Rutten GEHM, GrauwWJC, Nijpels G, et al. NHG-Standaard Diabetes mellitus type 2. Utrecht: NHG;2018.

2. RIVM. Bilthoven: RIVM, 2018. https://www.volksgezond heidenzorg.info/search/site/diabetes. Geraadpleegd op 26 december 2018.

3. Deakin T, McShane CE, Cade JE, et al. Group based training for self-management strategies in people with type 2 diabetes mellitus. Cochrane Database Syst Rev. 2005; https://doi.org/10.1002/14651858.cd003417.pub2.

4. Steinsbekk A, Rygg LO, Lisulo M, et al. Group based diabetes self-management education compared to routine treatment for people with type 2 diabetes mellitus. A systematic review with meta-analysis. BMC Health Serv Res. 2012;12:213.

5. Lorig KR, Holman H. Self-management education: history, definition, outcomes, and mechanisms. Ann Behav Med. 2003;26:1-7.

6. Tang TS, Funnell MM, Noorulla S, et al. Sustaining shortterm improvements over the long-term: results from a 2year diabetes self-management support (DSMS) intervention. Diabetes Res Clin Pract. 2012;95:85-92.

7. WolfJ. Niemand tussen wal en schip. Referentiekader maatschappelijke zorg voor mensen in multiprobleemsituaties. Nijmegen: Academische werkplaats OGGZ; 2015.

8. DeciEL, Ryan RM. The 'what' and 'why' of goal pursuits: human needs and the self-determination of behavior. Psychol Inq. 2000;11:227-68.

9. Rademakers J, Nijman J, Hoek L van der, et al. Measuring patient activation in the Netherlands: translation and validation of the American short form Patient Activation Measure (PAM13). BMC Public Health. 2012;12:577.

10. Hibbard JH, Stockard J, Mahoney ER, et al. Development of the Patient Activation Measure (PAM): conceptualizing and measuring activation in patients and consumers. Health ServRes. 2004;39(4 Pt 1):1005-26.

11. Peyrot M, Bushnell DM, BestJH, et al. Development and validation of the self-management profile for type 2 diabetes (SMP-T2D). Health Qual Life Outcomes. 2012;10:125.

12. Caro-Bautista J, Martin-Santos FJ, Morales-Asencio JM. Systematic review of the psychometric properties and theoretical grounding of instruments evaluating self-care in people with type 2 diabetes mellitus. J Adv Nurs. 2014;70:1209-27.

13. Rezal M,Emma M, Julinawati S, etal. Systematic review: the measurement of health self-efficacy to diabetes. AustJ Basic Appl Sci. 2013;7:295-302.

14. Aaronson NK, Muller M, Cohen PD, et al. Translation, validation, and norming of the Dutch language version of the SF-36 Health Survey in community and chronic disease populations. JClin Epidemiol. 1998;51:1055-68.

15. Gandek B, Ware JE, Aaronson NK, et al. Cross-validation of item selection and scoring for the SF-12 Health Survey in nine countries: results from the IQOLA Project. International Quality of Life Assessment. J Clin Epidemiol. 1998;51:1171-8. 